\title{
OLIGOCLONAL IgG BANDS IN THE CEREBROSPINAL FLUID OF PORTUGUESE PATIENTS WITH MULTIPLE SCLEROSIS
}

\section{Negative results indicate benign disease}

\author{
Maria José Sá1, Lucinda Sequeira², Maria Edite Rio ${ }^{3}$, Edward J. Thompson ${ }^{4}$
}

\begin{abstract}
We assessed the frequency of cerebrospinal fluid (CSF) restricted oligoclonal IgG bands (IgG$\mathrm{OCB}$ ) in Portuguese multiple sclerosis (MS) patients and its relationship with outcome. Paired CSF/serum samples of 406 patients with neurological disorders were submitted to isoelectric focusing with immunodetection of IgG. Ninety-two patients had definite MS; non-MS cases were assembled in groups inflammatory/infectious diseases (ID, $n=141)$ and other/controls (OD, $n=173)$. We found in the MS group: mean duration, 38.9 months; clinically isolated syndromes, 24\%; relapsing/remitting course (RR), $65 \%$; in RR patients the mean EDSS was 2.1 and the mean index of prog ression was 0.31 . Positive patterns significantly p redominated in MS (82.6\%; ID, 40.4\%; OD, 3.5\%). The sensitivity and the specificity of positive IgG-OCB for MS diagnosis was $82.6 \%$ and $79.9 \%$, respectively. The sole statistically significant difference in the MS $g$ roup was the lower prog ression index observed in negative cases. We conclude that the frequency of positive IgG-OCB patterns in our MS patients fits most values reported in the literature, and that negative results indicate benign disease.
\end{abstract}

KEY WORDS: multiple sclerosis, CSF, oligoclonal bands, IgG, isoelectric focusing.

\begin{abstract}
Bandas oligoclonais da IgG no líquido céfalo-raquidiano de doentes portugueses com esclerose múltipla: resultados negativos indicam doença benigna

RESUMO - Analisamos a frequência de bandas oligoclonais (BOC) restritas ao líquido céfalo-raquidiano (LCR) em doentes portugueses com esclerose múltipla (EM) e sua relação com a clínica. Determinaram-se por focagem isoeléctrica e imunodetecção as BOC da IgG em pares de amostras LCR/soro de 406 doentes com diversas patologias neurológicas: 92 tinham EM definitiva; os casos "não-EM" agruparam-se em doenças inflamatórias/infecciosas (ID; $n=141$ ) e outras/controles (OD; $n=173$ ). O grupo EM apresentava duração média: 38,9 meses; síndromes clinicamente isolados (CIS), 24\%; formas surto/remissão (RR), $65 \%$, nas quais se encontrou EDSS e índice de progressão médios de 2,1 e 0,31, respectivamente. O perfil positivo predominava significativamente na EM $(82,6 \%$; ID, 40,4\%; OD, 3,5\%), cuja sensibilidade e especificidade neste diagnóstico foi $82 \%$ e $79,9 \%$, respectivamente. A única diferença estatisticamente significativa no grupo EM foi o menor índice de progressão nos casos negativos. Em conclusão, a frequência de BOC positivas nos nossos doentes EM enquadrou-se nos valores da literatura, e a sua negatividade indicou evolução benigna.
\end{abstract}

PALAVRAS-CHAVE: esclerose múltipla, LCR, bandas oligoclonais, IgG, focagem isoeléctrica.

The intrathecal synthesis of antibodies has been since long recognised as a non-specific marker of inflammation in a variety of neurological disorders, particularly in multiple sclerosis (MS) 1 . Namely, the p resence of oligoclonal bands $(\mathrm{OCB})$ of immunoglobulin $\mathrm{G}(\mathrm{IgG})$ restricted to the cerebrospinal fluid
(CSF) of MS patients is the most sensitive parameter to evidence the inflammatory character of the disease $^{2,3}$. Yet, the final diagnosis of MS mainly relies upon the clinical features, due to the absence of specific biological markers.

The CSF analysis, as re g a ros the presence of IgG-

${ }^{1}$ Senior Neurologist, Head of Cerebrospinal Fluid (CSF) Unit, Head of Multiple Sclerosis (MS) Outpatient Clinical Care, Hospital S. João, Auxiliar Professor of Neuroanatomy, Porto Medical School, Porto, Portugal; ${ }^{2}$ Technician of CSF Unit, Hospital S. João, Porto, Portugal; '3Senior Neurologist, President of Center for Investigation and Treatment of Multiple Sclerosis of Hospital S. João, Porto, Potugal; ${ }^{4}$ PhD MD DSC FRCPath FRCP, Department of Neuroimmunology, National Hospital for Neurology \& Neurosurgery, The Institute of Neurology, Queen Square, London, U.K.

Received 24 November 2004. Accepted 21 February 2005.

Maria José Sá, MD - Department of Neurology, Hospital S. João - Alameda Professor Hernâni Monteiro - $4200-319$ Porto - Portugal. E-mail:mjsa@med.up.pt 
OCB and/or increased IgG Index, was included as a paraclinical exam in the classical study of Poser et al. ${ }^{4}$, as well as in the most recent diagnostic criteria of MS established by McDonald et al. ${ }^{5}$, essentially in clinically isolated syndromes (CIS) and primary progressive forms.

In the literature the frequency of OCB in MS varies from 56 to $97 \%$, depending on the methodology employed and the population studied ${ }^{3,6-11}$. In occidental populations these values are higher than in oriental ones, and this discrepancy has been ascribed to genetic differences ${ }^{7,11}$. This shows that the presence of CSF IgG-OCB is not constant in MS, although its absence is uncommon, leading some authors to advise an exhaustive diagnostic review ${ }^{3,12}$ in "negative" cases.

This study was designed to evaluate the results obtained in the detection of OCB in the CSF of Portuguese patients with definite MS, living in diffe rent regions of the country. In addition, we assessed the influence of clinical features, such as duration and course of the disease, in the laboratory results, in order to identify which factors might eventually be related with the absence of OCB in MS.

\section{METHOD}

Patients and study design - All subjects $(n=406)$ whose CSF and serum samples were consecutively studied in the CSF Laboratory of the Department of Neurology, Hospital S. João, Porto, in 2001 and 2002, to search the presence of IgG-OCB by isoelectric focusing (IEF), entered this study. The CSF samples were always obtained by lumbar puncture (LP), in patients attended at the Departments of Neurology from 9 Hospitals located in different regions of Portugal. In 17 cases more than one CSF sample was studied, but only the first one, which was collected for diagnostic purposes, was considered. The clinical data of all patients were gathered in the requests that a ccompanied the samples, in the clinical files of the Department of Neurology of Hospital S. João, and by questionnaires sent to the neurologists, as regards the patients assisted elsewhere. This allowed a confident knowledge of the final diagnosis at discharge and consequent accurate distinction between MS and non-MS patients, according to the criteria of McDonald et al. ${ }^{5}$, the acquisition of clinical features in MS patients, and the assembling of the remaining patients in other groups of diagnosis.

Thus, 92 patients $(22.7 \%)$ were seen to have definite $\mathrm{MS}^{5}$. According to the evolutive course, they were classified in the subgroups relapsing/remitting MS (RRMS), secondary prog ressive (SPMS) and primary progressive (PPMS); all patients with monosymptomatic presentation, i.e. clinical evidence of one relapse, plus imaging evidence of dissemination in time and space, were compiled in the group of clinically isolated syndromes (CIS).
The following parameters were recorded in the MS group, and in each evolutive subgroup: sex; age at LP; duration of disease as measured in months since the onset symptoms until the time of LP. In the patients with RRMS, the disability and the severity were also determined, as follows: the disability was assessed with the Expanded Disability Status Scale (EDSS) and the severity was calculated by the Poser's index of progression ${ }^{13}$, i.e. the EDSS score divided by the duration of the disease previously expressed in months.

The non-MS patients were assembled in 2 groups according to the underlying pathology: 141 (34.7\%) presented infectious/inflammatory disorders of the nervous system (ID); the remaining $173(42.6 \%)$ displayed other $\mathrm{n}$ e u rological diseases/controls (OD). The three most frequent diagnosis in groups ID and OD were meningitis, encephalitis and neurosyphilis, and ischaemic cerebrovascular disease, neurodegenerative disorder and spondilotic myelopathy, respectively. Nine patients conforming to the category of possible $\mathrm{MS}^{5}$ were included in the ID group. In 14 subjects with functional symptoms of the nervous system, the exhaustive study did not disclose any neurological disorder.

Laboratoryproced ures - The CSF and serum samples we recollected at the same time in each patient and were immediately sent refrigerated to the CSF Laboratory of the Department of Neurology of Hospital de S. João. After reception, small aliquots were prepared and kept frozen at $-20^{\circ} \mathrm{C}$ for a few days until processing. To detect the IgG-OCB, paired CSF/serum samples of every case were run in parallel by IEF followed by passive protein transfer to a nitrocellulose membrane and immunodetection of IgG with double antibody, according to the method described by Keir et al. ${ }^{14}$. Minor technical adaptations were done locally, as for instance the refrigeration value, which was set at $+15^{\circ} \mathrm{C}^{15}$. CSF restricted OCB were considered in case of at least two bands present in the CSF and absent in serum ${ }^{14}$. The patterns were classified according to the five types defined by consensus of the Committee of the E u ropean Concerted Action for Multiple Sclerosis (Charcot Foundation) $)^{2}$, which allows the distinction of local

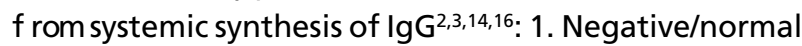
- absence of OCB in the CSF and serum; 2. Positive - CSF restricted OCB; 3. "Greater than" - restricted CSF OCB and additional OCB in the CSF and serum; 4. "Mirror" - identical OCB in the CSF and serum; 5. Paraprotein - monoclone in the CSF and serum. The cases with patterns of types 2 and 3 were joined in the classification "positive", given that they both traduce intrathecal synthesis of antibodies. The identification of the IEF patterns was done in all cases by two authors ( $M J S$ and $L S$ ) who were unaware of each other's results and of the clinical diagnosis.

The internal quality control was performed according to the literature ${ }^{2,3,14}$, recently confirmed by an International Consensus Group ${ }^{16}$ : in each run, one CSF sample with positive pattern and another one with negative pattern 
we re included. For external quality control, seven paired $\mathrm{CSF} /$ se rumsamples of MS cases with negative OCB were sent to a European reference laboratory: Department of Neuroimmunology, Institute of Neurology, National Hospital for Neurology and Neurosurgery, Queen Square, London, UK; a concordance of the results in both laboratories was seen in 6 cases; the remaining CSF sample was positive for IgG-OCB, instead of negative.

Analysis of CSF results versus clinical data - The number of different OCB patterns was determined, as well as their relative distribution by group of patients. In the MS group, we analysed the distribution of the OCB patte rrs by sex, age, type of evolution or clinical course, duration, and in RRMS cases, severity.

The sensitivity of the technique was calculated by the percentage of patients with definite MS and positive CSF patterns. To assess the specificity of the technique we de$t$ e rmined the percentage of patients with other diseases (controls) whose CSF was positive for OCB, and then the quotient between the number of cases with negative patterns and the total number of controls; we did two calculations assuming as control group either the sum of groups ID and OD or the group OD alone.

Statistical analysis - The following tests were performed: Chi-square (distribution of CSF patterns by groups of patients); Mann-Whitney's U and Kruskal-Wallis methods (relationship between clinical data and CSF OCB pattemin the MS group); Fisher exact test to determine the influence of duration, severity and progression index in the presence or absence of OCB. Differences were considered statistically significant when $\mathrm{P}<0.05$.

\section{RESULTS}

With respect to the clinical features of the MS group, we found a predominance of female $(n=57)$ over male $(n=35)$ sex (ratio: $1.6 / 1)$. The mean age of the whole group was 37.1 years \pm 12.5 (range: 16 - 73 years); higher values were seen in the females (37.8 years \pm 12.5$)$ than in males ( 35.9 years \pm 12.7), difference that almost reached the significant level $(P=0.0507)$. As regards the clinical course, the distribution of the cases was as follows: RR, $60(65 \%)$; SP, 5 (5\%); PP, 4 (4\%), CIS, 22 (24\%). The remaining patient was a woman with Devic's disease ${ }^{17}$. No differences were found in the distribution of these forms by sex. We observed that the mean age was higher in patients with PP (63.3 years) and SP (51.5 years) forms than in patients with RR course (48.8 years) or CIS (34 years), but significant differences were detected only between RR and CIS cases ( $p$ $<0.03$ ). We found a wide range in the duration of the disease ( 1 month to 40 years), with mean value of 38.9 months \pm 76.2 ; yet, in $70 \%$ cases the dura-
Table 1. Data of MS patients with relapsing/remitting forms.

\begin{tabular}{|c|c|c|c|}
\hline & Mean & Range & $\mathrm{n}$ \\
\hline Duration (months) & $45.7 \pm 88.3$ & $1-480$ & 60 \\
\hline EDSS & $2.1 \pm 1.8$ & $0.0-8.0$ & 60 \\
\hline $0.0-3.0$ & - & - & 44 \\
\hline $3.5-6.0$ & - & - & 13 \\
\hline $6.5-8.0$ & - & - & 3 \\
\hline Index of progression & $0.31 \pm 0.7$ & 0.0 to 3.5 & 60 \\
\hline$\leq 0.13$ & - & - & 38 \\
\hline$>0.13$ & - & - & 22 \\
\hline
\end{tabular}

MS, multiple sclerosis; EDSS, expanded disability status scale.

tion was lower than 2 years. Duration was significantly higher $(P<0.05)$ in females ( 50.8 months) than in males (39.4 months). Moreover, statistically significant differences were found in the duration values by MS form $\left(P<10^{-3}\right)$, the mean value of which was lowest in patients with CIS (21.9 months) and $\mathrm{g}$ reatest in SP cases (69.1 months). The clinical data assessed in the RRMS subgroup, as regards duration (mean: 45.7 months), EDSS scores and the Poser's index of progression (cut-off value: 0.13 ) are presented in Table 1.

The results obtained in the CSF study are shown in Table 2. We found that the positive type of OCB pattern predominated both in the MS $(82.6 \%)$ and ID $(40.4 \%)$ groups, whereas the negative pattern was mainly noticed in the OD group ( $82 \%)$; these differences observed in the distribution of CSF patte rns according to the groups of patients were statistically significant $\left(\chi^{2}, P<10^{-4}\right)$. The sensitivity of the positive OCB pattern in MS had a mean value of $82.6 \%$; moreover, it was higher in the progressive forms $(100 \%)$ than in RRMS $(81.7 \%)$ or in patients with CIS (81.8\%). On the contrary, the specificity was lower, since positive OCB were detected in all groups of patients: $3.5 \%$ of OD cases and $20 \%$ of all non-MS patients. Hence, the specificity values varied according to the control group considered: $79.9 \%$ (ID and OD groups) and $96.5 \%$ (OD group alone). Conversely, the negative pattern was found in 189 out of 406 cases (46.5\%), constituting, as a whole, the most frequent pattern.

As specifically regards the MS group (Table 1), we observed CSF restricted OCB in 76 patients, $p$ resenting diffe rent types of clinical course as alluded to above, 18 of which had also a few OCB in the se rum (Type 3 pattern). A negative pattern was seen in 15 patients (16\%), including 11 cases with RR clinical course. In this RRMS group we found highly significant differences (Fisher exact test, $\mathrm{P}<10^{-4}$ ) in the correlation between the CSF patterns and the 
Table 2. Distribution of IgG oligoclonal patterns in all groups of patients.

\begin{tabular}{lccccccccc}
\hline OCB pattern & RR & SP & PP & CIS & Devic & $n$ & ID & OD & Total \\
\hline Positive & 49 & 5 & 4 & 18 & - & 76 & 57 & 6 & 139 \\
Negative & 11 & - & - & 3 & 1 & 15 & 32 & 142 & 189 \\
Mirror & - & - & - & 1 & - & 1 & 51 & 25 & 77 \\
Paraprotein & - & - & - & - & - & 0 & 1 & 0 & 1 \\
Total & 60 & 5 & 4 & 22 & 1 & 92 & 141 & 173 & 406 \\
\hline
\end{tabular}

OCB, oligoclonal bands; MS, multiple sclerosis; RR, relapsing/renitting; SP, secondary prog ressive; PP, primary prog ressive; CIS, clinically isolated syndrome; ID, infectious/inflammatory diseases of the nervous system; OD, other neurological disorders/controls.

severity of the disease: the patients with negative patterns presented a more "benign" course, i.e. lower progression indexes, than those with positive ones. In effect, the progression index was smaller than the cut-off level in 8 patients with negative pattern, whereas it was higher than 0.13 in the remaining 3 negative cases. In one patient with CIS a "mirror" pattern was detected. Finally, differences were also noticed in the correlation of patterns with age, which was higher in negative patients (42.8 years \pm 13.4 ) than in those with CSF restricted IgGOCB (35.9 years \pm 12.1$)$, almost reaching the significant level $(P=0.053)$. In contrast, no statistically significant relations were found between the $O C B$ results and any of the other clinical parameters: sex, clinical course and duration.

\section{DISCUSSION}

In this study we have for the first time assessed the frequency of locally restricted IgG-OCB in the CSF of Portuguese patients with definite diagnosis of MS. This endeavour was accomplished through the collaboration that the CSF Laboratory of the Department of Neurology of Hospital S. João, Porto, provides to the Departments of Neurology of several Hospitals in the country, in the determination of OCB with IEF and immunodetection of $\mathrm{IgG}$, according to the laboratorial procedures recommended in the literature ${ }^{2,3,6}$. Furthermore, it turned feasible to collect a relevant number of MS cases in 2 years and to obtain precise and detailed clinical data in all patients.

We have found that $82.6 \%$ of MS patients present positive patterns. This value is higher than those described in oriental populations - $56.1 \%^{7,11}$ - and in Finland $-76 \%{ }^{6}$, but lower than the values reported in Brazil, $85 \%{ }^{9}$, in Spain, $87.7 \%{ }^{10}$ and, particu-

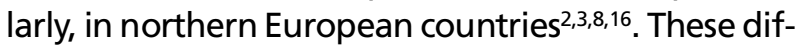
ferences have been ascribed to immunogenetic factors which influence the intrathecal immune humoral functions in human populations $\mathrm{s}^{7,11}$, although the role of different laboratory procedures and techniques may also explain, at least in part, the dis- c repancy of values reported in the literature $\mathrm{e}^{2,3,6-11,16}$. Moreover, we have included patients with CIS in our estimations, whereas Falip et $\mathrm{al}^{10}$ set that specific group of patients apart, so that the reported value of $87.7 \%$ positive patterns in their study refers exclusively to patients with clinically defined $\mathrm{MS}^{10}$. Hence, one might assume that the frequency of positive patterns in our study would be greater if we didn't include the CIS group, too. Anyway, the frequency of the positive pattern in the CIS group that we found $(81.8 \%)$ is considerably higher than it was found in other series $-54.8 \%^{10}$ and $62.5 \%{ }^{18}$, which may be somehow explained by differences in the criteria of inclusion of these cases. In effect, as previously described, all patients with CIS in our study had imagiological evidence of dissemination in time and in space.

In $16 \%$ MS patients, we did not find local production of IgG. Interestingly, these cases with negative patterns presented lower indexes of progression, indicating a more benign course of the disease, nicely fitting the results of Zeman et al. ${ }^{12}$ and strengthening the suggestion of other studies ${ }^{19,20}$ that the absence of $O C B$ at the time of diagnosis indicates a trend towards a better prognosis. Moreover, alike other reports our OCB negative patients were on the average older than those with positive patterns; however, in that study there was also a predominance of male sex, later age of onset and chronicp ro g ressive forms in OCB negative cases ${ }^{6}$, differe nces which we did not notice. On the contrary, a study conducted at Japan failed to demonstrate differences in the clinical course and disability in MS patients with or without $\mathrm{OCB}$ in the $\mathrm{CSF}^{7}$. We are aware that the absence of $O C B$ is rare in MS and that "false negative" is a potential situation ${ }^{12}$, although in the present study it seems unlikely, given the external quality control that was provided in a reference European laboratory ${ }^{3,14}$.

As regards the presence of "mirror" pattern in one patient with $\mathrm{CIS}$, no sound explanation could be advanced to explain this bizarre finding. Indeed, 
this type of pattern is very unusual in MS, given that the serum oligoclonal answer which may be found in this disease, as happened in some of our patients, is additional to the typical intrathecal answer ${ }^{21,22}$. In this sense, the meaning of the "mirror" pattern is MS is similar to the negative pattern, since they both traduce absence of local synthesis of IgG.

In addition, as concerns the distribution of the CSF OCB patterns in the totality of patients, our results are in accordance with Falip et al. ${ }^{10}$ and with a previous review of our laboratory ${ }^{23}$, stressing that the p redominance of OCB negative patterns might be explained by the large number of patients without inflammatory neurological disorder. On the other hand, the observation of positive patterns in different groups of neurological diseases is a widely recognized fact $^{3}$. However, we found a lower frequency of positive patterns in all groups of patients than Falip et al. ${ }^{10}$, mainly in the OD group, which may be due to differences in the composition of control groups.

Finally, the sensitivity value of the positive $O C B$ patterns for the diagnosis of MS that we found $82.6 \%$ - fits most studies ${ }^{8-10,24}$, particularly in those ca rried out in Spanish $-87.7 \%{ }^{10}$ and Brazilian populations $-85 \%{ }^{9}$. Inversely, the specificity was lower than the sensitivity, although our values were higher than those reported by others, which varied from 45 to $62 \%{ }^{10,24}$, perhaps reflecting differences in the control groups, too. The well-known lack of specificity of the positive OCB pattern in the diagnosis of MS is due to the considerable number of patients with inflammatorydiseases of the nervous system included. Anyway, in agreement with Falip et al. ${ }^{10}$, the specificity reached higher values when the controls were confined to the patients of the OD group.

In conclusion, we emphasise that the great majority of Portuguese MS patients have CSF restricted IgG-OCB, the frequency of which is quite similar to the values observed in specific populations. Up to now, the role played by the presence of eventual similar immunogenetical factors in these results is unknown. Moreover, this study reinforces the better prognosis of MS patients with negative OCB patterns.

Acknowledgements - We want to thank our colleagues Dr. Alfredo Sá (Hospital Santo André, Leiria), Dr. António Carne iro(Hospital Militar Regional n. ${ }^{\circ}$, Porto), Dr. Armando Morganho (Centro Hospitalar do Funchal, Madeira), Dr. José Figueiredo (Hospital S. Marcos, Braga), Dr. José Pinto Marques (Hospital S. Bernardo, Setúbal), Dr. ${ }^{a}$ Maria Lurdes Rodrigues (Hospital Senhora da Oliveira, Guimarães), Dr. ${ }^{a}$ Maria Vaz Pato (Centro Hospitalar Cova

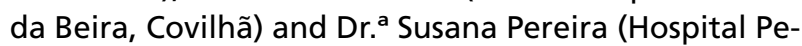
dro Hispano, Matosinhos) for making the clinical data available. Thanks are also due to Professor Joaquim Marques de Sá, Departamento de Engenharia Electrotécnica e de Computadores, Faculty of Engineering, University of Porto, as statistical reviewer. Finally, we are grateful to Aventis Pharma Lda., Octapharma, Schering Lusitana, Lda., Schering-Plough-Farma, Lda and Serono Produtos Farmacêuticos Lda. for their financial support.

\section{REFERENCES}

1. Link H. Immunoglobulin $G$ and low molecular weight proteins in human CSF. Chemical and immunological characterization with special reference to MS. Acta Neurol Scand 1967;28(Suppl):S1-S36.

2. Andersson M, Alvarez-Cermeno J, Bernardi G, et al. Cerebrospinal fluid in the diagnosis of multiple sclerosis: a consensus report. J Neurol Neurosurg Psychiatry 1994;57:897-902.

3. Thompson EJ. Cereb rospinal fluid. J Neurol Neurosurg Psychiatry 1995;59:349-357.

4. Poser CM, Paty DW, Scheinberg L, et al. New diagnostic criteria for multiple sclerosis: guidelines for researh protocols. Ann Neurol 1983;13:227-231.

5. McDonald WI, Compston A, Edan G, et al. Recommended diagnostic criteria for multiple sclerosis: Guidelines from the international panel on the diagnosis of multiple sclerosis. Ann Neurol 2001;50:121-127.

6. Pirttila T, Nurmikko T. CSF oligoclonal bands, MRI, and the diagnosis of multiple sclerosis. Acta Neurol Scand 1995;92:468-471.

7. Fukazawa T, Kikuchi S, Sasaki H, et al. The significance of oligoclonal bands in multiple sclerosis in Japan: relevance of immunogenetic backgrounds. J Neurol Sci 1998;158:209-214.

8. Seres E, Bencsik K, Rajda C, Vecsei L. Diagnostic studies of cerebrospinal fluid in patients with multiple sclerosis. Orv Hetil 1998;139:1905-1908.

9. Puccioni-Sohler M, Passeri F, Oliveira C, Brandão CO, Papaiz-Alvarenga R. Multiple sclerosis in Brazil: analysis of cerebrospinal fluid by standard methods. Arq Neuropsiquiatr 1999;57:927-931.

10. Falip M, Tintore M, Jardi R, Duran I, Link H, Montalban X. Clinical usefulness of oligoclonal bands. Rev Neurol 2001;32:1120-1124.

11. Kikuchi S, Fukasawa T, Niino M, et al. HLA-related subpopulations of MS in Japanese with and without oligoclonal IgG bands. Neurology 2003;60:647-651.

12. Zeman AZJ, Kidd D, McLean BN, et al. A study of oligoclonal band negative multiple sclerosis. J Neurol Neurosu rgPsychiatry 1996;60:27-30.

13. Poser S, Raun NE, Poser W. Age at onset, initial symptomatology and the course of multiple sclerosis. Acta Neurol Scand 1982;66:355-362.

14. Keir G, Luxton RW, Thompson EJ. Isoelectric focusing of cerebrospinal fluid immunoglobulin G: an annotated update. Ann Clin Biochem 1990;27:436-443.

15. Sá MJ, Sequeira L, Rio ME, et al. Prevalência de bandas oligoclonais da IgG no líquido céfalo-raquidiano de doentes com esclerose múltipla. Sinapse 2003;2:10-16.

16. Reiber H, Thompson EJ, Grimsley G, et al. Quality assurance for cerebrospinal fluid protein analysis: international consensus by an internetbased group discussion. Clin Chem Lab Med 2003;41:331-337.

17. Wingerchuk DM, Hogancamp WF, O'Brien PC, Weinshenker BG. The clinical course of neuromyelitis optica (Devic's syndrome). Neurology 1999;53:1107-1114

18. Tintore M, Rovira A, Brieva L, et al. Isolated demyelinating syndromes: comparison of CSF oligoclonal bands and different MR imaging criteria to predict conversion to CDMS. Mult Scler 2001;7:359-363.

19. Avasarala JR, Cross AH, Trotter JL. Oligoclonal band number as a marker for prognosis in multiple sclerosis. Arch Neurol 2001;58:2044-2045.

20. Mesaros S, Drulovic J, Levic Z. Clinical characteristics and neurophysiologic findings in patients with multiple sclerosis without oligoclonal IgG in cerebrospinal fluid. Srp Arh Celok Lek 2003;131:122-126.

21. Zeman A, McLean B, Keir G, Luxton R, Sharief M, Thompson E. The significance of serum oligoclonal bands in neurological diseases. J Neurol Neurosurg Psychiatry 1993;56:32-35.

22. Zeman AZ, Keir G, Luxton R, Thompson EJ. Serum oligoclonal IgG is a common and persistent finding in multiple sclerosis and has a systemic source. QJM 1996;89:187-193.

23. Carvalho M, Nadais G, Sequeira L, Campos MM, Sá MJ. Detecção de bandas oligoclonais da IgG no LCR por focagem isoeléctrica num laboratório de LCR: casuística de um ano. Sinapse 2001;1:55.

24. Siddiqui I, Aleem S, Kayani N, Baig S. CSF oligoclonal bands in multiple sclerosis. J Pak Med Assoc 2002;52:351-353. 